\title{
Analysis of mechanical characteristics of superconducting field coil for 17 MW class high temperature superconducting synchronous motor
}

\author{
J. H. Kim, S. I. Park, S. H. Im, and H. M. Kim* \\ Jeju National University, Jeju \\ (Received 19 August 2013; revised or reviewed 25 September 2013; accepted 26 September 2013)
}

\begin{abstract}
Superconducting field coils using a high-temperature superconducting (HTS) wires with high current density generate high magnetic field of 2 to $5[\mathrm{~T}]$ and electromagnetic force (Lorentz force) acting on the superconducting field coils also become a very strong from the point of view of a mechanical characteristics. Because mechanical stress caused by these powerful electromagnetic force is one of the factors which worsens the critical current performance and structural characteristics of HTS wire, the mechanical stress analysis should be performed when designing the superconducting field coils. In this paper, as part of structural design of superconducting field coils for $17 \mathrm{MW}$ class superconducting ship propulsion motor mechanical stress acting on the superconducting field coils was analyzed and structural safety was also determined by the coupling analysis system that is consists of commercial electromagnetic field analysis program and structural analysis program.
\end{abstract}

Keywords : electromagnetic force, high magnetic field, mechanical stress, superconducting field coil

\section{1. 서 론}

초전도 전동기는 동일한 면적에서 구리보다 100배 이상의 전류 통전 능력을 갖는 초전도 선재를 계자에 사용하기 때문에 동일 용량의 기존 전동기보다 고 자기장을 발생하여 무게와 크기를 크게 줄일 수 있는 이점을 갖는다.

이러한 초전도 전동기를 선박추진용 전기 추진 시스템의 추진 전동기로 대체할 경우 동일한 출력을 발생시키는 기존의 동기 전동기 대비 무게는 약 $33 \%$ 가 가벼워지고 크기는 $40 \%$ 가 줄어든다. 이러한 소형, 경량화의 장점으로 인해 선박 설계에 대한 유연성과 선박 활용에 있어 효율성을 높여줄 뿐만 아니라 고온초전도 선재를 사용함에 따른 여자 손실을 줄여 저손실 및 고효율화와 비자성체를 사용한 공심형 타입의 고정자 사용으로 인한 저진동, 저소음화를 실현 할 수 있다. 또한 여자 손실 감소로 인해 저부하에서의 효율이 일반 기기보다 높으며 기존 전동기보다 $1 / 5 \sim 1 / 3$ 의 낮은 동기 리액턴스로 인해 부하변동에 따른 과도 안정성을 향상 시킬 수 있는 등 많은 장점을 취할 수 있다[1].

초전도 회전기는 공심형 구조로 인해 계자에서는 높은 암페어-턴(ampere-turns)을 필요로 하기 때문에 높은 자기장이 초전도 계자코일에 작용하고 이에 따른 전자기력이 매우 커지게 된다. 또한 테이프 형태의 고온 초전도 선재를 사용한 racetrack 형태의 초전도 계자코일의 단부에서 고 자기장이 집중되므로 전자기력 또한 계자코일의 직선부보다 곡선부에서 커지게 된다[2]. 이러한 전자기력은 초전도 선재의 구조적 안전성에

* Corresponding author: hmkim@jejunu.ac.kr
영향을 미칠 뿐 아니라 선재에 통전 가능한 임계전류를 감소시킨다. 따라서 초전도 계자코일에 작용하는 기계적 응력 분포를 해석하여 초전도 계자 코일의 최적화 설계를 통한 신뢰성 확보가 중요하다. 본 논문에서는 상용 전자장 유한요소 해석 프로그램과 구조 유한요소 해석 프로그램을 이용한 연성 해석 방법을 통하여 선박 추진용 $17 \mathrm{MW}$ 급 고온 초전도 전동기의 계자코일의 자기장분포 및 전자기력 해석을 수행 하였으며 racetrack 형태의 초전도 계자코일 단부에 작용하는 반경 응력(radial stress), 후프 응력(hoop stress) 그리고 압축 응력(compressive stress)을 포함한 각종 기계적 응력을 해석하여 초전도 계자 코일을 구성하는 초전도 선재와 insulating plate, bobbin block에 사용되는 재질의 항복강도와 기계적 응력 값을 통하여 초전도 계자코일의 구조적 안정성을 판단하였다.

\section{2. 초전도 계자코일 구조 설계와 해석}

\section{1. 초전도 계자 코일 설계}

본 논문에서 해석하고자 하는 $17 \mathrm{MW}$ 선박추진용 초전도 전동기의 계자코일은 그림 1 에 나타낸 것처럼 9 개의 double-pancake 코일로 구성되며 각 pancake 코일 층간을 절연하는 insulating plate를 포함한다. 1 극의 계자 코일에 사용된 고온 초전도 선재량은 $30.45 \mathrm{~km}$ 이며 6044 턴으로 권선 되었다. 계자코일의 축 방향 길이는 $1745.71 \mathrm{~mm}$ 이며 단부를 제외한 축 방향 직선부 길이는 $1100 \mathrm{~mm}$ 이다. 


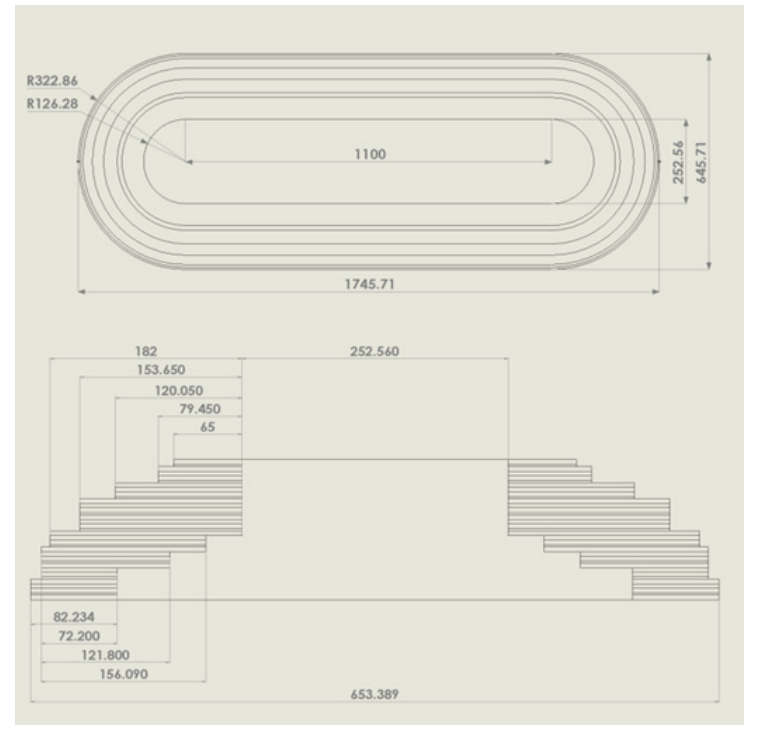

Fig. 1. Schematic view of HTS racetrack field coil for 17 MW Class high temperature superconducting synchronous motor.

TABLE I

SPECIFICATIONS OF HTS WIRE.

\begin{tabular}{cc}
\hline Conductor Property & Value \\
\hline Conductor type & Bi-2223 \\
Thickness [mm] & 0.35 \\
Width [mm] & 4.6 \\
Critical current [A] @77 K, SF & $\geq 180$ \\
Critical tensile strength [MPa] @77 K & 270 \\
Critical tensile strain [\%] @77 K & 0.4 \\
\hline
\end{tabular}

표 1 은 본 논문에서 기계적 특성을 해석하고자 하는 초전도 계자 코일 설계에 사용된 Sumitomo사의 $\mathrm{Bi}-2223$ 고온초전도 선재의 사양을 보여준다. 사용된 초전도 선재는 $4.6 \mathrm{~mm}$ 의 폭, $0.35 \mathrm{~mm}$ 의 두께를 가지며 임계전류와 구조적 안전성을 결정하는 항복강도는 $77 \mathrm{~K}$, 자기 자기장 하에서 각각 $180 \mathrm{~A}, 270 \mathrm{MPa}$ 이다[3].

\section{2. 초전도 계자 코일 전자장 해석}

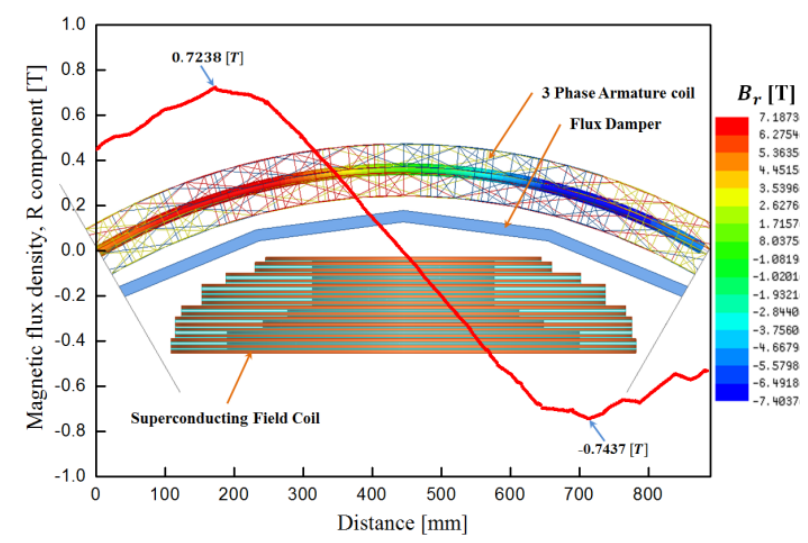

Fig. 2. Magnetic flux density distribution of the radial direction at the armature coil air gap.

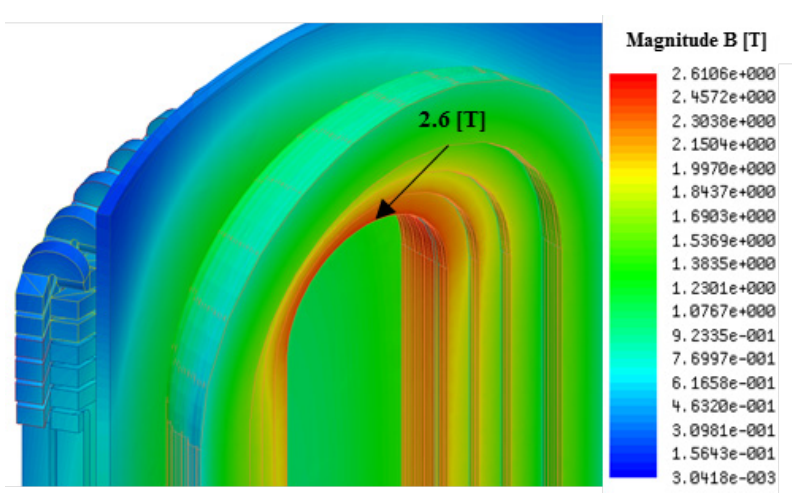

(a)

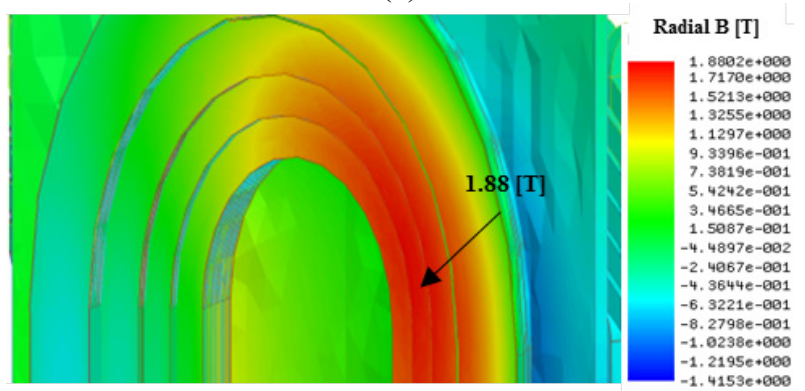

(b)

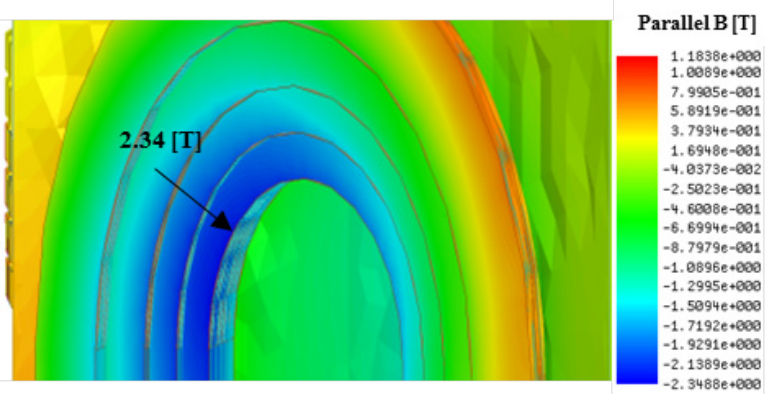

(c)

Fig. 3. Three-dimensional magnetic field distribution at the curvature parts of the HTS field Coil: (a) Composite value of the magnetic field, (b) Radial components of the magnetic field, (c) Parallel components of the magnetic field.

그림 2는 $17 \mathrm{MW}$ 급 초전도 전동기의 전자장 해석을 위한 해석 모델과 전동기 출력에 직접적으로 연관되는 3상 전기자 코일 공극에서의 자속 밀도 분포를 나타낸다. 상용 전자장 해석 프로그램을 통해 설계된 3차원 전자장 해석모델은 초전도 계자코일 (superconducting field coil), 플럭스 댐퍼(flux damper) 그리고 3상 전기자 코일 (3 phase armature coil)을 포함한다.

초전도 계자코일에서 발생되는 자속과 3상 전기자 코일의 회전 자속이 상호 작용하여 초전도 전동기의 회전 토크를 만들어내므로 전기자 코일 공극에서의 쇄교 자속 밀도 값은 전자장 해석시 매우 중요한 파라미터 중 하나가 된다. 전기자 코일 공극에서의 자속 밀도 값을 해석한 결과 최대 쇄교 자속 값은 0.7437 [T]로 측정되었다.

그림 3 은 초전도 계자코일의 3 차원 자기장분포를 나타낸다. 계자 코일 운전전류 $91 \mathrm{~A}$ 와 전기자 정격 전류 $1487 \mathrm{~A}$ 를 여자하여 전동기 정격 운전시 자기장 분포를 해석한 결과 racetrack형 계자코일의 단부에서의 최대 자기장은 $2.61 \mathrm{~T}$ 였으며 반경 응력과 후프 응력을 결정하는 


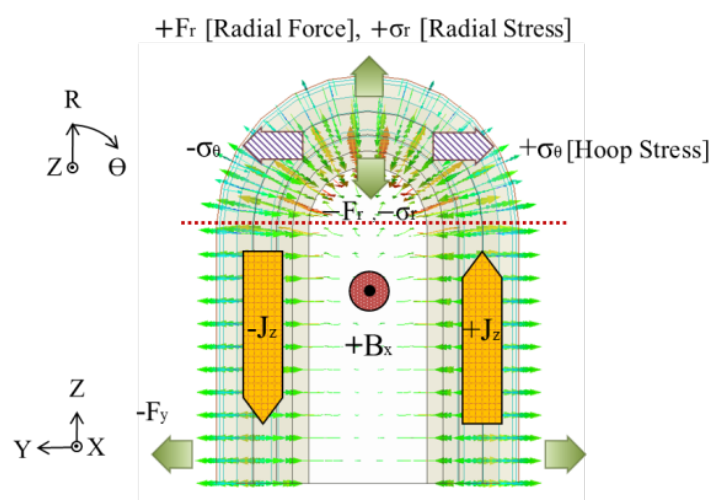

$-\mathrm{Fx}_{\mathrm{x}}$ [Compressive Force], $-\sigma_{c}$ [Compressive Stress]

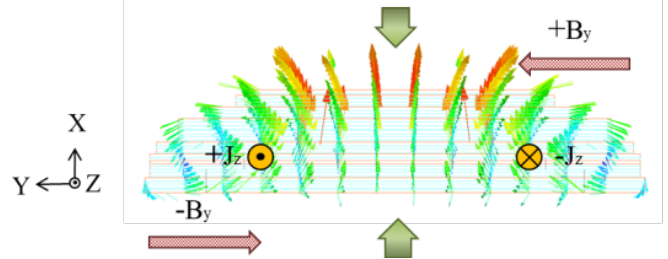

Fig. 4. Diagram of the electromagnetic force and mechanical stress acting on the HTS field coil.

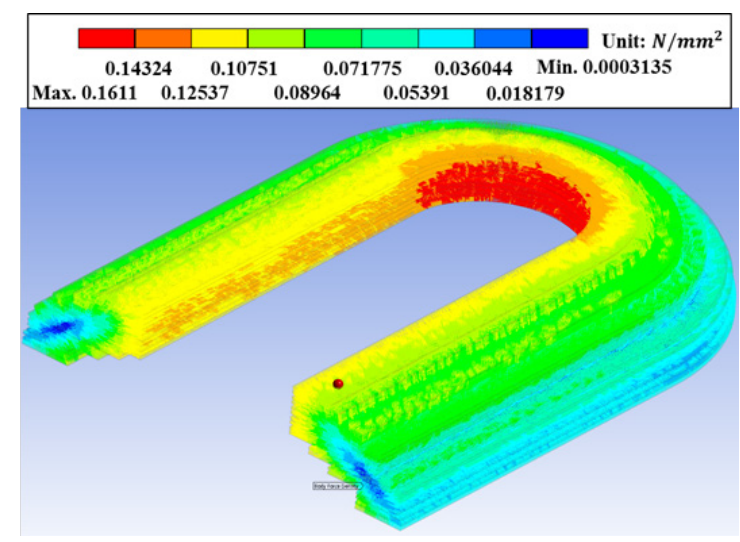

Fig. 5. Distribution of electromagnetic force at the curvature part of racetrack field coil.

수평 자기장의 최대값은 $2.34 \mathrm{~T}$, 압축 응력을 결정하는 수직 자기장의 최대값은 $1.88 \mathrm{~T}$ 였다.

초전도 선재에 작용하는 Lorentz force density $\mathrm{F}$ 는 다음과 같은 식으로 표현할 수 있다.

$$
\mathrm{F}=\mathrm{J} \times \mathrm{B}
$$

여기서 $\mathrm{J}$ 는 전류밀도 $\left(\mathrm{A} / \mathrm{m}^{2}\right), \mathrm{B}$ 는 자속 밀도 $(\mathrm{T})$ 를 나타낸다.

그림 4는 식 (1)에 근거한 초전도 계자 코일에 발생하는 방향별 자기장 성분에 따라 작용하는 전자기력과 기계적 응력을 나타내는 개념도이다. 초전도 선재면을 기준으로 수평방향의 자기장 $\left(\mathrm{B}_{\mathrm{x}}\right)$ 성분에 의해 발생되는 Lorentz force가 반경 응력과 단부에서의 후프 응력으로 작용하며 수직방향의 자기장 $\left(\mathrm{B}_{\mathrm{y}}\right)$ 성분으로 인해 compressive force가 전단응력(shear stress)인 압축 응력으로 작용하게 된다[4].
TABLE II

ELECTROMAGNETIC STRESS VALUES AFFECTED IN EACH LAYER OF THE HTS FIELD COIL.

\begin{tabular}{ccccc}
\hline Layer & $\mathrm{F}(\mathrm{X})[\mathrm{N}]$ & $\mathrm{F}(\mathrm{Y})[\mathrm{N}]$ & $\mathrm{F}(\mathrm{Z})[\mathrm{N}]$ & $\mathrm{Mag} \mathrm{F}[\mathrm{N}]$ \\
\hline $1 \mathrm{SP}$ & 39559.1 & 506.802 & 7727.7 & 40310 \\
$2 \mathrm{SP}$ & 43075.2 & 565.689 & 9271.25 & 44065 \\
$3 \mathrm{SP}$ & 37157.3 & 629.696 & 10079.6 & 38505 \\
$4 \mathrm{SP}$ & 57424.5 & 1026.01 & 12571.8 & 58793 \\
$5 \mathrm{SP}$ & 46720.6 & 1009.05 & 13696.7 & 48697 \\
$6 \mathrm{SP}$ & 54950.7 & 1362.5 & 13863.8 & 56689 \\
$7 \mathrm{SP}$ & 40018.1 & 1343.14 & 14966.5 & 42746 \\
$8 \mathrm{SP}$ & 22253.2 & 1315.47 & 15814.1 & 27332 \\
$9 \mathrm{SP}$ & 7160.07 & 1303.55 & 16825.7 & 18332 \\
$10 \mathrm{SP}$ & 519.995 & 1656.18 & 15449.1 & 15546 \\
$11 \mathrm{SP}$ & -6078.59 & 1413.83 & 10874.5 & 12538 \\
$12 \mathrm{SP}$ & -23007.1 & 1539.68 & 10631.1 & 25391 \\
$13 \mathrm{SP}$ & -21242.3 & 1258.39 & 5956.98 & 22097 \\
$14 \mathrm{SP}$ & -36893 & 1266.36 & 6711.75 & 37519 \\
$15 \mathrm{SP}$ & -17820 & 827.022 & 656.962 & 17851 \\
$16 \mathrm{SP}$ & -26977.3 & 866.454 & 504.492 & 26996 \\
$17 \mathrm{SP}$ & 35022.7 & 872.314 & 1116.04 & 35051 \\
$18 \mathrm{SP}$ & -45385.4 & 860.812 & 1498.83 & 45418 \\
\hline
\end{tabular}

* Mag F presents composite value of the Lorentz force, $\mathrm{F}(\mathrm{X})$ presents $\mathrm{X}$ components of the Lorentz force, $\mathrm{F}(\mathrm{Y})$ presents $\mathrm{Y}$ components of the Lorentz force and $\mathrm{F}(\mathrm{Z})$ presents $\mathrm{Z}$ components of the Lorentz force

그림 5는 그림 4 를 바탕으로 초전도 계자 코일 주변에 발생하는 고 자기장에 의해 생성되는 전자기력의 분포를 보여준다. 일반적으로 racetrack형태의 초전도 계자코일의 자기장분포는 단부에서 집중하게 되는 양상을 보임에 따라 전자기력 또한 단부에서 최대 값을 보인다. 따라서 전자기력의 분포와 방향을 파악하여 기계적 응력 해석시 초전도 계자코일에 작용하는 기계적 응력의 분포와 크기의 양상을 예상할 수 있다.

표2는 각 single pancake (SP) 코일에 작용하는 방향 별

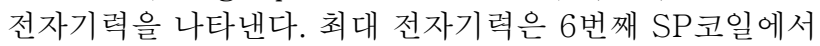
발생하며 전반적으로 상, 하부 코일로 갈수로 큰 값을 보였다.

\section{3. 초전도 계자 코일 기계적 응력 해석}

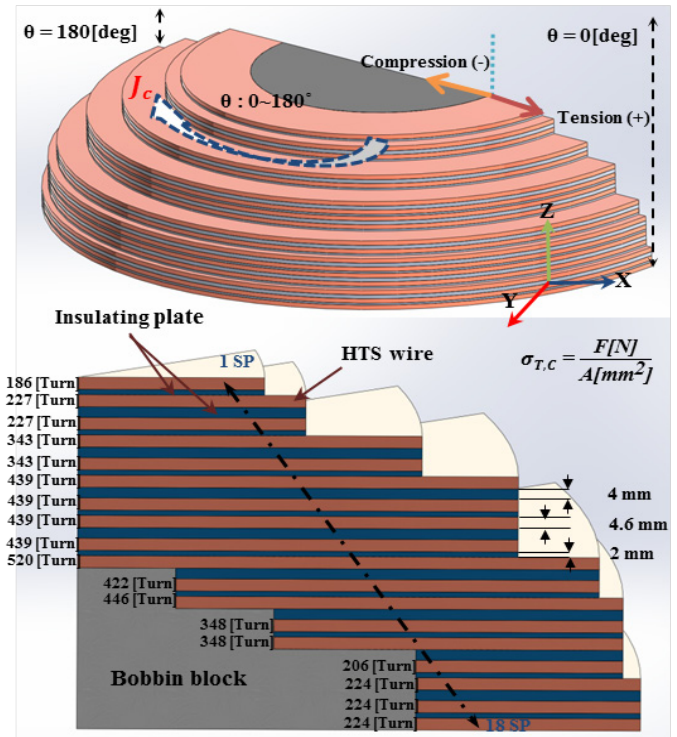

Fig. 6. Overview of the analysis model for mechanical stress analysis at the curvature part of HTS field coil. 
TABLE III

MECHANICAL PROPERTIES OF STRUCTURAL ANALYSIS OF HTS FIELD

\begin{tabular}{ccc} 
& COIL. & \\
\hline Items & HTS Coil & Bobbin block \\
{$[\mathrm{Bi}-2223]$} & \& Insulating plate \\
\hline Mass density $\left[\mathrm{kg} / \mathrm{m}^{3}\right]$ & 4989 & 2823 \\
Young's modulus [GPa] & 63.7 & 70 \\
Poisson's ratio & 0.18 & 0.33 \\
Shear modulus [GPa] & 26.992 & 26.316 \\
Tensile yield strength & 270 & 503 \\
{$[\mathrm{MPa}]$} & & \\
\hline
\end{tabular}

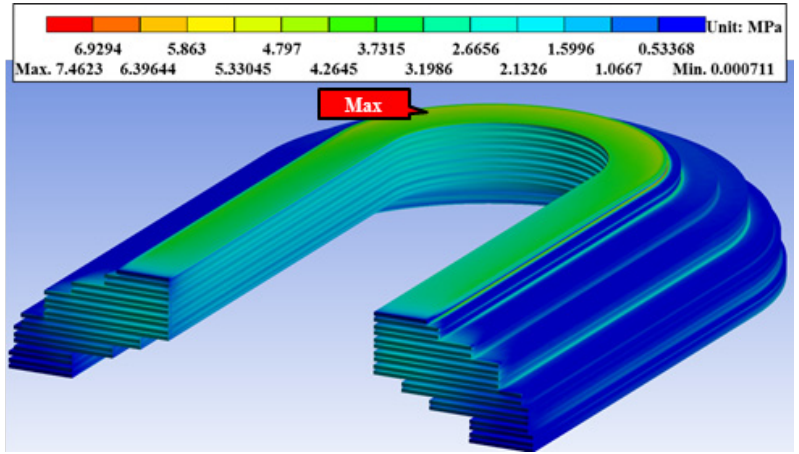

Fig. 7. The equivalent stress distribution at the double-pancake racetrack field coil.

그림 6은 초전도 계자코일에 발생하는 기계적 응력을 계산하기 위한 해석 모델을 보여주며 표 3은 기계적 응력 해석에 필요한 사용재료의 물성치를 나타낸다 [5]. bobbin block과 insulating plate에는 기기의 중량을 줄이기 위해 비교적 질량밀도가 작고 기계적 강도가 큰 알루미늄을 사용하였다.

원통좌표계가 적용되는 racetrack형 초전도 계자코일의 단부에서 발생하는 기계적 응력은 다음의 평면응력의 변환공식(transformation equation for the plane stress)에 의해 구할 수 있다 [6], [7].

$$
\begin{aligned}
& \sigma_{\text {radial }}=\frac{\sigma_{x}+\sigma_{y}}{2}+\frac{\sigma_{x}-\sigma_{y}}{2} \cos 2 \theta+\tau_{x y} \sin 2 \theta \\
& \sigma_{\text {hoop }}=\frac{\sigma_{x}+\sigma_{y}}{2}-\frac{\sigma_{x}-\sigma_{y}}{2} \cos 2 \theta-\tau_{x y} \sin 2 \theta
\end{aligned}
$$

여기서 $\sigma_{\mathrm{x}}, \sigma_{\mathrm{y}}$ 는 $\mathrm{x}, \mathrm{y}$ 방향으로 작용하는 수직응력, $\tau_{\mathrm{xy}}$ 는 $\mathrm{xy}$ 면에 작용하는 전단응력을 말한다. 그리고 $\theta$ 는 0도에서 180 도 범위를 가지며 원통좌표계가 적용되는 racetrack형 계자코일 단부에서 응력이 작용하는 지점의 각도를 말한다. 위 변환공식을 통해 직각좌표축에서 원통좌표축으로 응력 성분을 변환시킬 수 있다. 초전도 계자코일에 작용하는 기계적응력을 반경 응력 $(\mathrm{X}$ or $\mathrm{R}$ 성분)과 후프 응력 ( $\mathrm{Y}$ or $\theta$ 성분)그리고 압축응력 ( $\mathrm{Z}$ 성분)으로 나눠 계산하였으며 각 성분의 응력은 인장 $(+)$ 과 압축 $(-)$ 으로 표현된다. 그림 7 은 초전도 계자코일의 단부에서 발생하는 등가 응력의 최대값을 보여준다. 구조물의 파단이나 소성변형의 기준이 되는 등가응력(equivalent stress)을 통해 초전도 계자코일의 구조적 안전성을 판단한 결과, 2 층 $\mathrm{SP}$ 코일에서 최대 등가응력이 발생하였으며 그 크기는 $7.46 \mathrm{MPa}$ 이다. 이는 본 설계에 사용된 $\mathrm{Bi}-2223$ 고온초전도 선재의 최대 항복강도인 $270 \mathrm{MPa}$ 에 훨씬 못 미치는 값으로 전자기력에 의한 초전도 계자코일에
작용하는 기계적 응력은 무시해도 될만한 수준으로 구조적 안전성은 매우 양호한 것으로 판단된다.

TABLE IV

RADIAL STRESS AT THE CURVATURE PART OF DOUBLE-PANCAKE RACETRACK FIELD COIL.

\begin{tabular}{ccccccc}
\hline & \multicolumn{3}{c}{ Tension $(+)$} & \multicolumn{3}{c}{ Compression (-) } \\
Layer & $\begin{array}{c}\text { Angle } \\
\text { Value }\end{array}$ & Turns & $\begin{array}{c}\text { Angle } \\
{[\mathrm{deg}]}\end{array}$ & $\begin{array}{c}\text { Value } \\
{[\mathrm{MPa}]}\end{array}$ & Turns \\
\hline $1 \mathrm{SP}$ & 47 & 1.114 & 178 & 42 & 1.371 & 185 \\
$2 \mathrm{SP}$ & 60 & 8.443 & 184 & 4 & 0.278 & 212 \\
$3 \mathrm{SP}$ & 70 & 2.654 & 1 & 123 & 0.243 & 222 \\
$4 \mathrm{SP}$ & 33 & 3.915 & 228 & 152 & 0.068 & 320 \\
$5 \mathrm{SP}$ & 60 & 2.742 & 1 & 89 & 0.248 & 328 \\
$6 \mathrm{SP}$ & 60 & 2.685 & 1 & 115 & 1.005 & 338 \\
$7 \mathrm{SP}$ & 65 & 2.558 & 1 & 67 & 0.573 & 365 \\
$8 \mathrm{SP}$ & 56 & 2.479 & 1 & 86 & 0.679 & 365 \\
$9 \mathrm{SP}$ & 54 & 2.404 & 1 & 83 & 0.872 & 383 \\
$10 \mathrm{SP}$ & 104 & 2.479 & 1 & 74 & 2.946 & 433 \\
$11 \mathrm{SP}$ & 91 & 1.844 & 1 & 81 & 0.991 & 307 \\
$12 \mathrm{SP}$ & 65 & 2.505 & 1 & 97 & 0.926 & 287 \\
$13 \mathrm{SP}$ & 38 & 1.180 & 1 & 105 & 0.8 & 188 \\
$14 \mathrm{SP}$ & 32 & 2.103 & 1 & 110 & 0.897 & 144 \\
$15 \mathrm{SP}$ & 22 & 0.384 & 1 & 110 & 0.641 & 98 \\
$16 \mathrm{SP}$ & 20 & 0.595 & 1 & 25 & 1.238 & 204 \\
$17 \mathrm{SP}$ & 23 & 0.514 & 1 & 109 & 0.409 & 120 \\
$18 \mathrm{SP}$ & 22 & 0.359 & 1 & 11 & 0.528 & 223 \\
\hline
\end{tabular}

* Turns present the number of winding turns of each single pancake coil

TABLE V

HOOP STRESS AT THE CURVATURE PART OF DOUBLE-PANCAKE

\begin{tabular}{|c|c|c|c|c|c|c|}
\hline \multirow[b]{2}{*}{ Layer } & \multicolumn{3}{|c|}{ Tension (+) } & \multicolumn{3}{|c|}{ Compression (-) } \\
\hline & $\begin{array}{l}\text { Angle } \\
{[\mathrm{deg}]}\end{array}$ & $\begin{array}{c}\text { Value } \\
\text { [MPa] }\end{array}$ & Turns & $\begin{array}{l}\text { Angle } \\
{[\mathrm{deg}]}\end{array}$ & $\begin{array}{l}\text { Value } \\
\text { [MPa] }\end{array}$ & Turns \\
\hline $1 \mathrm{SP}$ & 90 & 1.026 & 1 & 41 & 1.332 & 185 \\
\hline $2 \mathrm{SP}$ & 40 & 2.607 & 184 & N/A & N/A & N/A \\
\hline $3 \mathrm{SP}$ & 75 & 1.096 & 1 & N/A & $\mathrm{N} / \mathrm{A}$ & N/A \\
\hline $4 \mathrm{SP}$ & 58 & 1.789 & 228 & $\mathrm{~N} / \mathrm{A}$ & $\mathrm{N} / \mathrm{A}$ & N/A \\
\hline $5 \mathrm{SP}$ & 80 & 1.321 & 1 & N/A & N/A & N/A \\
\hline $6 \mathrm{SP}$ & 85 & 1.384 & 1 & 179 & 0.065 & 338 \\
\hline $7 \mathrm{SP}$ & 90 & 1.381 & 1 & N/A & N/A & N/A \\
\hline $8 \mathrm{SP}$ & 85 & 1.371 & 1 & N/A & N/A & N/A \\
\hline $9 \mathrm{SP}$ & 84 & 1.313 & 1 & N/A & N/A & N/A \\
\hline $10 \mathrm{SP}$ & 90 & 1.364 & 1 & 0 & 0.813 & 433 \\
\hline $11 \mathrm{SP}$ & 100 & 1.079 & 1 & 180 & 0.225 & 333 \\
\hline $12 \mathrm{SP}$ & 105 & 1.272 & 1 & 177 & 0.213 & 324 \\
\hline $13 \mathrm{SP}$ & 70 & 0.685 & 1 & $\mathrm{~N} / \mathrm{A}$ & N/A & N/A \\
\hline $14 \mathrm{SP}$ & 61 & 0.989 & 1 & 0 & 0.2 & 224 \\
\hline $15 \mathrm{SP}$ & 23 & 0.208 & 1 & 19 & 0.216 & 200 \\
\hline $16 \mathrm{SP}$ & 60 & 0.183 & 1 & 24 & 0.527 & 204 \\
\hline $17 \mathrm{SP}$ & 70 & 0.172 & 1 & 19 & 0.186 & 181 \\
\hline $18 \mathrm{SP}$ & 22 & 0.367 & 1 & 11 & 0.560 & 223 \\
\hline
\end{tabular}
RACETRACK FIELD COIL.

* N/A means not measured, Turns present the number of winding turns of each single pancake coil 
TABLE VI

COMPRESSIVE STRESS AT THE CURVATURE PART OF DOUBLE-PANCAKE RACETRACK FIELD COIL.

\begin{tabular}{ccccccc}
\hline & \multicolumn{3}{c}{ Tension (+) } & \multicolumn{4}{c}{ Compression (-) } \\
Layer & $\begin{array}{c}\text { Angle } \\
\text { Value }\end{array}$ & Turns & $\begin{array}{c}\text { Angle } \\
{[\mathrm{MPa}]}\end{array}$ & $\begin{array}{c}\text { Value } \\
{[\mathrm{MPa}]}\end{array}$ & Turns \\
\hline $1 \mathrm{SP}$ & 89 & 4.71 & 1 & 42 & 6.013 & 185 \\
$2 \mathrm{SP}$ & 29 & 4.449 & 184 & 29 & 0.784 & 193 \\
$3 \mathrm{SP}$ & 35 & 1.404 & 184 & 2 & 0.06 & 226 \\
$4 \mathrm{SP}$ & 33 & 2.863 & 221 & 26 & 0.429 & 328 \\
$5 \mathrm{SP}$ & 35 & 0.736 & 220 & 109 & 0.915 & 342 \\
$6 \mathrm{SP}$ & 97 & 0.537 & 1 & 86 & 1.157 & 338 \\
$7 \mathrm{SP}$ & 111 & 0.306 & 1 & 1 & 0.949 & 329 \\
$8 \mathrm{SP}$ & 83 & 0.263 & 1 & 2 & 1.022 & 420 \\
$9 \mathrm{SP}$ & 36 & 0.424 & 1 & 33 & 1.778 & 428 \\
$10 \mathrm{SP}$ & 108 & 1.069 & 1 & 136 & 2.980 & 432 \\
$11 \mathrm{SP}$ & 56 & 0.578 & 1 & 2 & 1.340 & 332 \\
$12 \mathrm{SP}$ & 80 & 1.592 & 1 & 5 & 1.337 & 315 \\
$13 \mathrm{SP}$ & 70 & 0.396 & 1 & 18 & 1.278 & 217 \\
$14 \mathrm{SP}$ & 70 & 1.683 & 1 & 18 & 1.231 & 224 \\
$15 \mathrm{SP}$ & N/A & N/A & N/A & 21 & 1.544 & 205 \\
$16 \mathrm{SP}$ & 68 & 0.160 & 223 & 84 & 2.026 & 200 \\
$17 \mathrm{SP}$ & 76 & 0.164 & 1 & 17 & 1.0962 & 195 \\
$18 \mathrm{SP}$ & 24 & 1.684 & 1 & 10 & 2.585 & 223 \\
\hline
\end{tabular}

* Turns present the number of winding turns of each single pancake coil

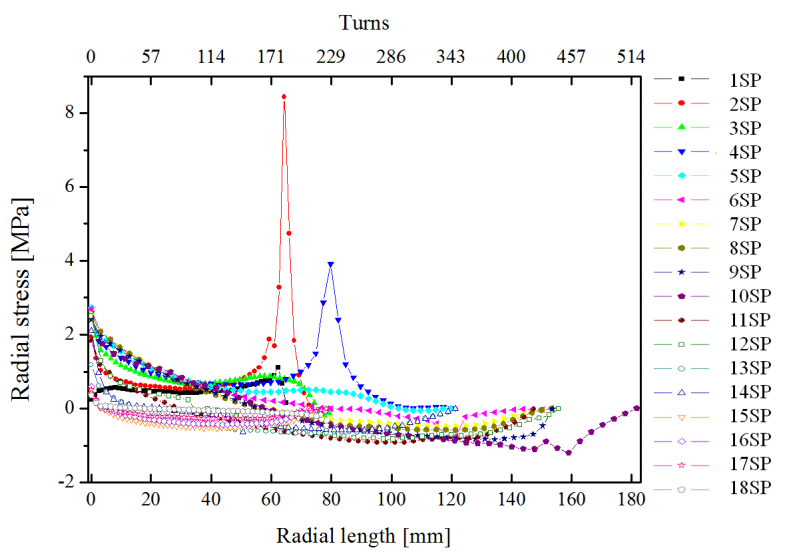

(a)

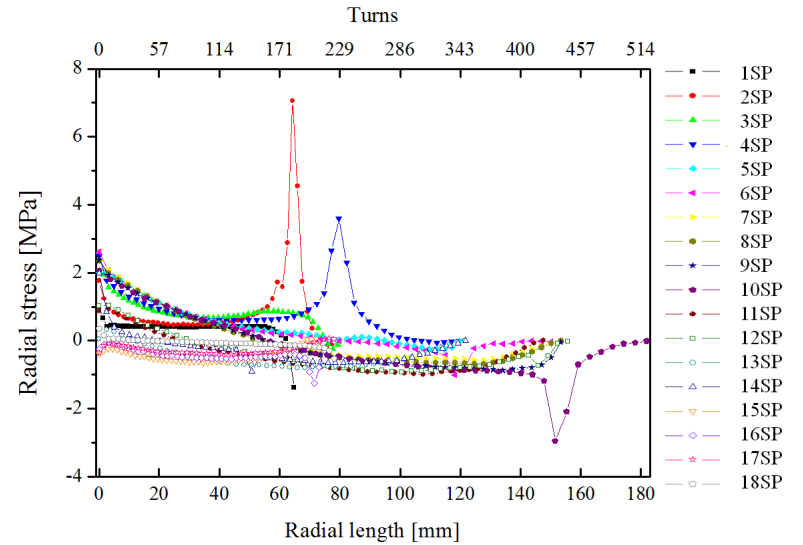

(b)

Fig. 8. Maximum radial stress variation in the radial direction at the curvature part of each single pancake coil; (a) Tension (+), (b) Compression (-).

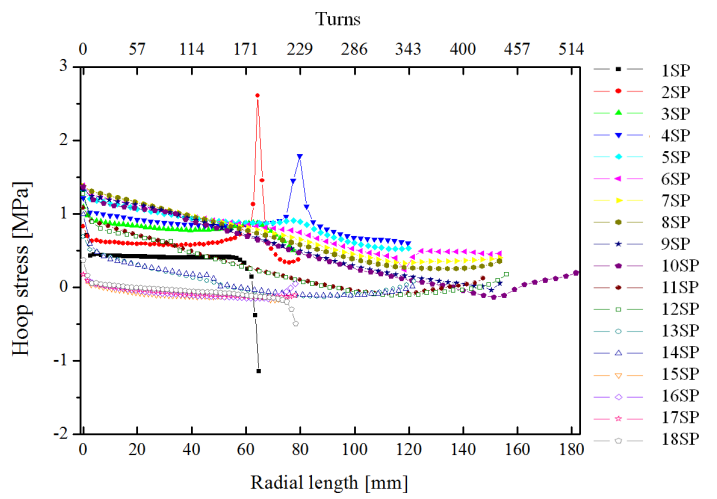

(a)

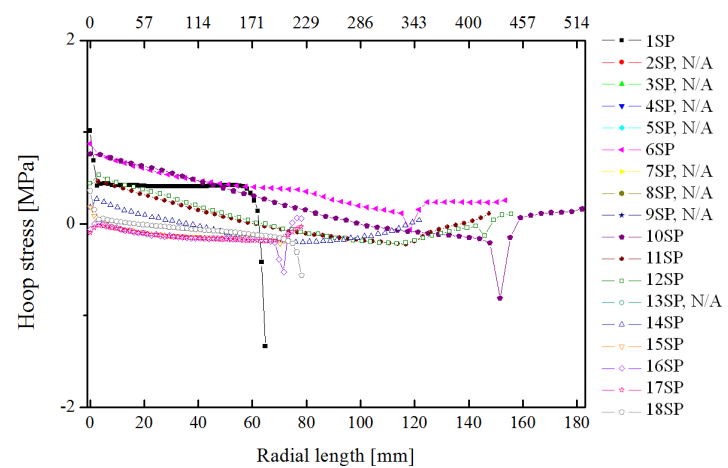

(b)

Fig. 9. Maximum hoop stress variation in the radial direction at the curvature part of each single pancake coil; (a) Tension (+), (b) Compression (-).

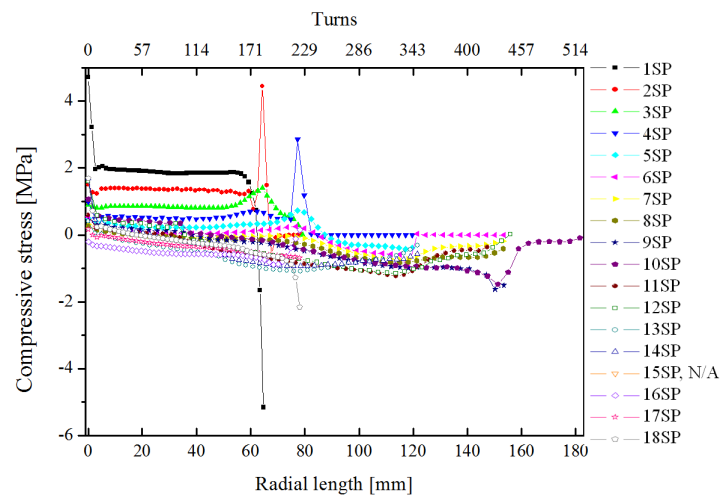

(a)

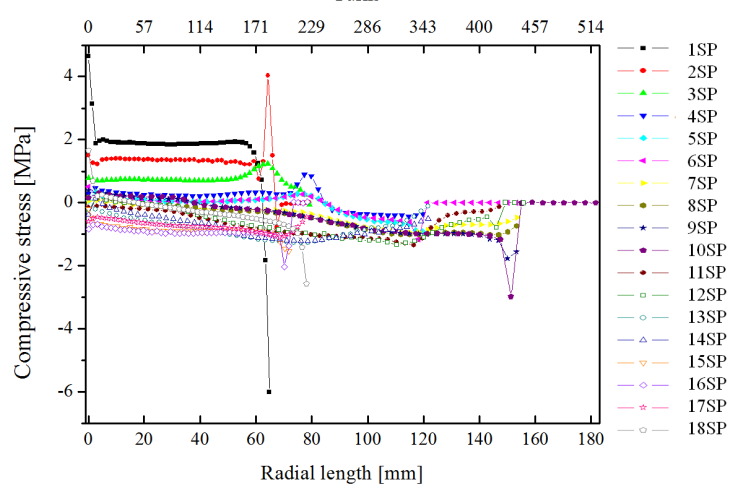

(b)

Fig. 10. Maximum compressive stress variation in the radial direction at the curvature part of each single pancake coil; (a) Tension (+), (b) Compression (-). 
표 4, 5, 6은 각각 racetrack 형 초전도 계자코일의 1 에서 18 층까지의 각 $\mathrm{SP}$ 코일 단부에서 발생하는 반경 응력, 후프 응력 그리고 압축응력의 최대값과 응력 발생 지점을 나타낸다. 대체적으로 인장 방향과 압축 방향 중 반경 응력과 후프 응력은 인장하는 방향의 응력이 비교적 큰 값을 보였으며 압축 응력은 압축하는 방향의 응력이 큰 값을 보였다. 또한 인장하는 기계적 응력은 단부 내경 근처의 권선에서 발생하였으며 압축하는 기계적 응력은 외경 근처의 권선에서 발생하였다.

그림 $8,9,10$ 은 각 $\mathrm{SP}$ 코일의 단부에서 권선방향인 반경방향으로 발생하는 기계적 응력의 변화를 나타낸다. 각 $\mathrm{SP}$ 코일에서 최대 응력이 발생하는 위치를 파악하기 위해 최대응력이 발생하는 지점에서 반경방향으로 발생하는 응력변화를 측정하였다. racetrack 형 초전도 계자코일의 단부에서 발생하는 최대 반경 응력은 2 층 $\mathrm{SP}$ 코일의 184 턴에서 발생하며 그 크기는 $8.44 \mathrm{MPa}$ 이다. 또한 최대 후프 응력도 최대 반경 응력과 동일한 위치에서 발생하며 그 크기는 $2.6 \mathrm{MPa}$ 이다. 마지막으로 단부에서 발생하는 압축 응력은 1 층 $\mathrm{SP}$ 코일의 185 번째 권선에서 발생하였으며 그 크기는 $6 \mathrm{MPa}$ 으로 측정 되었다.

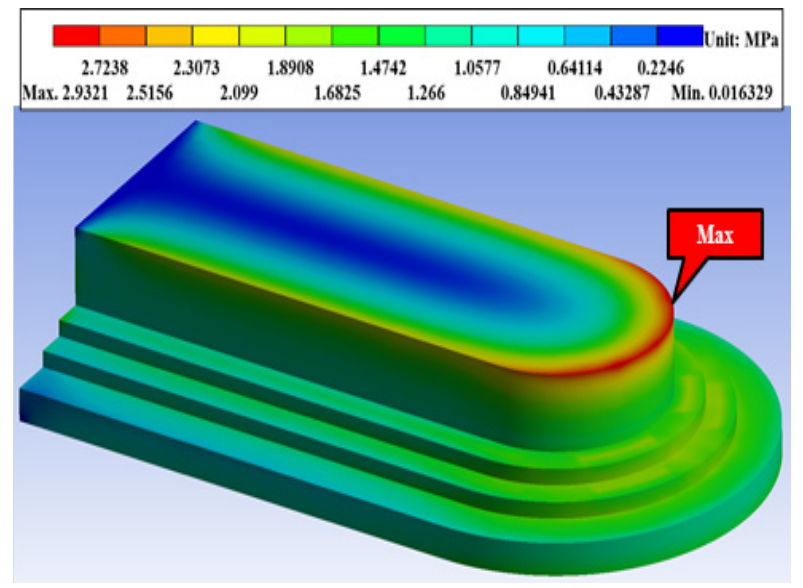

Fig. 11. The equivalent stress distribution at the bobbin block.

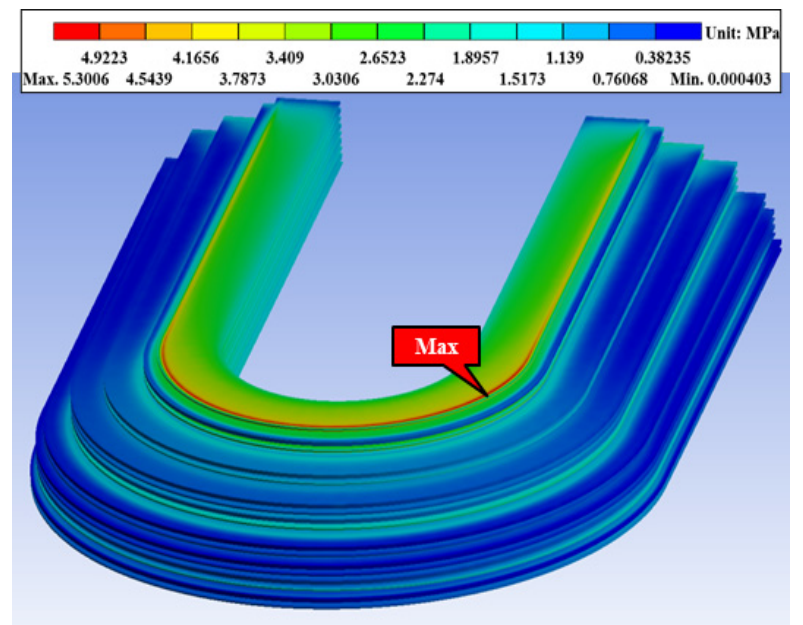

Fig. 12. The equivalent stress distribution at the insulating plate.

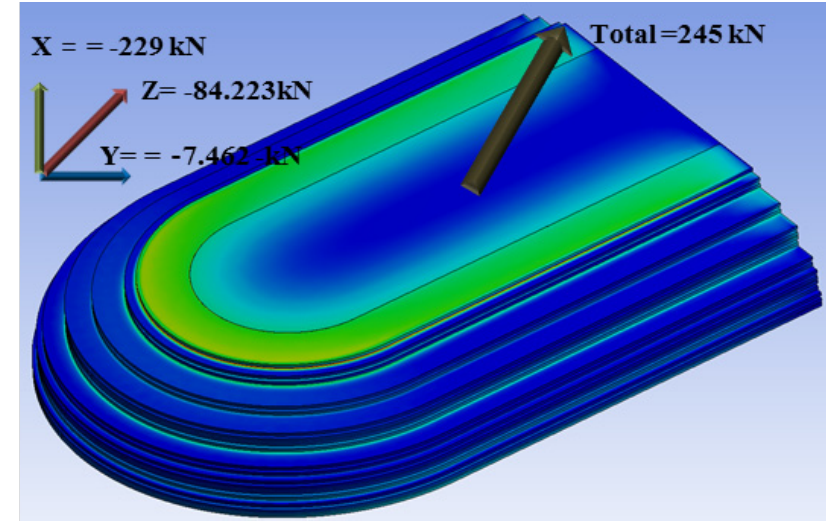

Fig. 13. Reaction force acting on the superconducting field coils.

그림 11은 초전도 선재를 지지하는 bobbin block에 작용하는 등가응력 분포를 나타내며 그림 12 는 pancake 코일 층간을 절연하는 insulating plate에서의 등가응력 분포를 보여준다. bobbin block과 insulating plate에서 발생하는 최대 등가응력은 각각 $2.9,5.3 \mathrm{MPa}$ 으로 사용재료인 알루미늄의 최대 항복강도인 $503 \mathrm{MPa}$ 보다 훨 씬 작은 크기로 계산되었다.

그림 13은 bobbin cover와 물리적으로 맞닿는 $1 \mathrm{SP}$ 의 상부와 bobbin block 상부에서의 반발력을 나타낸다. 총 반발력은 $245 \mathrm{kN}$ 이며 그 중 $\mathrm{X}$ 방향의 반발력 성분이 대부분을 차지하므로 최소한 $245 \mathrm{kN}$ 의 힘으로 보빈 커버를 고정해야 초전도 계자코일을 전자기력에 의해 bobbin block으로부터 밀려나는 것을 방 지할 수 있다.

\section{3. 결 론}

본 논문에서는 선박추진용 전기 추진 전동기로 사용하기 위한 $17 \mathrm{MW}$ 급 초전도 전동기 계자코일의 기계적 응력 해석을 통하여 구조적 안전성을 판단 하였다.

상용 전자장 유한 요소 해석 프로그램을 사용하여 초전도 계자코일의 자기장 분포와 전자기력을 해석한 후 구조 해석 프로그램을 연성 해석하여 각종 기계적 응력분포를 해석 한 결과, racetrack 형태로 설계된 초전도 계자코일의 전자기적, 기계적 안전성 판단의 기준이 되는 단부에서의 최대 수직 자기장과 수평 자기장은 각각 $1.88,2.34 \mathrm{~T}$ 로 계산되었다. 수평자기장으로 인해 생기는 Lorentz force 에 의해 초전도 계자 코일 단부에서 발생하는 최대 반경 응력과 후프 응력은 2 번째 $\mathrm{SP}$ 코일에서 발생하였으며 그 크기는 각각 $8.44,2.6 \mathrm{MPa}$ 이다. 마지막으로 수직 자기장으로 인해 발생되는 최대 압축 응력은 첫 번째 $\mathrm{SP}$ 코일에서 $6.01 \mathrm{Mpa}$ 의 크기로 계산되었다. 결론적으로 초전도 선재의 구조적 안전성 판단의 기준이 되는 최대 등각응력은 $7.46 \mathrm{MPa}$ 으로 초전도 계자코일에 사용된 $\mathrm{Bi}-2223$ 고온초전도 선재의 최대 항복강도인 $270 \mathrm{MPa}$ 을 통한 안전율은 약 36 배의 여유를 갖는다.

하지만 본 연구에서는 초전도 계자코일이 전자기적, 기계적으로 가장 취약할 수 있는 3상 단락 이 발생한 경우를 고려 하지 않았다. 따라서 추후의 연구를 통하여 3상단락시 초전도 계자코일에 미치는 자기장 분포의 영향과 그에 따른 
기계적 응력의 변화를 해석하여 초전도 계자코일의 최적화된 전자기적, 구조적 설계를 수행 할 예정이다.

\section{ACKNOWLEDGMENT}

This work was supported by the International Collaborative R\&D Program and the Power Generation \& Electricity Delivery of the Korea Institute of Energy Technology Evaluation and Planning (KETEP) grant funded by the Korea government Ministry of Trade, industry \& Energy. (20118520020020), (20113020020020)

\section{REFERENCES}

[1] Youngkil Kwon, Seungkyu Baik, Development of core technology to commercialize a superconducting rotating machine, Korea Research Council for Industrial Science \& Technology, 2012.
[2] Jihyung Kim, Sall Park, and Homin Kim, "Magnetic field analysis of the field coil for $10 \mathrm{MW}$ Class superconducting wind turbines," Superconductivity and Cryogenics, vol. 14, no. 3, pp. 18-22, 2012.

[3] Seungkyu Baik, Youngkil Kwon, Sail Park, and Homin Kim, "performance analysis of a superconducting motor for higher efficiency design," IEEE Trans. Appl. Supercond., vol. 23, no. 3, 2013.

[4] S.B. Kim, T. kadota, J.H. Joo, H. Sano, S. Murase, S.H. Lee, J.P. Hong, H.M. Kim, Y.K. Kwon, Y.S. Jo, "A study on electromagnetic and mechanical characteristics of the field coil in HTS motor," Physica C, vol. 470, no. 20, pp. 1756-1762, 2010.

[5] Charles P. Poole, Jr., "Handbook of Superconductivity," Department of Physics and Institute of Superconductivity University of South Carolina, pp. 577-592, 2000.

[6] K. Kim, S. Kim, S. Kim, M. park, I. K. Yu, J. K. Lee, S. Y. Lee, K. Choi, K. C. Seong, and H. K. Yeom, "Stress Analysis for Toroid-Type HTS SMES Coil and Bobbin Structure Considering Large Parallel Magnetic Field, "IEEE Trans. Appl. Supercond., vol. 21, no. 3, pp. 2275-2278, 2011.

[7] James M. Gere, Barry Goodno, "Mechanics of Materials, SI Edition $7^{\text {th }}$ Edition," CENGAGE Learning, pp. 541-542, 2011. 